\title{
SiCKNESS ABSENCE AND SEARCH UNEMPLOYMENT
}

\author{
BERTIL HOLMLUND
}

CESIFO WORKING PAPER NO. 1227

CATEgory 3: Social Protection

JUNE 2004

\footnotetext{
An electronic version of the paper may be downloaded

- from the SSRN website:

www.SSRN.com

- from the CESifo website:

www.CESifo.de
} 


\title{
Sickness Absence and Search Unemployment
}

\begin{abstract}
The paper presents a model that allows a unified analysis of sickness absence and search unemployment. Sickness appears as random shocks to individual utility functions, interacts with individual searchand labor supply decisions and triggers movements across labor force states. The employed worker prefers absence for sufficiently severe sickness and the unemployed worker may prefer nonparticipation if the disutility of search is amplified by sickness. The decisions governing labor force transitions are influenced by social insurance benefits available for sick or unemployed workers. We examine how these benefits affect individual decisions on absence and search and the implications for employment, unemployment and nonparticipation. The normative analysis of the socially optimal benefit structure suggests that there is, in general, a case for benefit di.erentiation across states of non-work. In particular, there is a case for a benefit structure that rewards active job search.
\end{abstract}

JEL Classification: J21, J64, J65.

Keywords: sickness absence, search, unemployment, sickness benefits, unemployment benefits.

\author{
Bertil Holmlund \\ Department of Economics \\ Uppsala University \\ Box 513 \\ SE-75120 Uppsala \\ Sweden \\ Bertil.Holmlund@nek.uu.se
}

I am grateful to Per Engström, Peter Fredriksson, Ann-Sofie Kolm and seminar participants at Uppsala University for useful comments. The paper was in part written during a visit to UBC Vancouver. I thank the Economics department for its hospitality. 


\section{Introduction}

Sickness absence represents a considerable loss of work-time, often of the same order of magnitude as the loss associated with unemployment. Some forms of sickness absence are clearly involuntary from the worker's perspective, such as absence caused by severe accidents or diseases. Other forms of sickness absence are best described as voluntary adjustments to changes in preferences for leisure or the value of home production. When contractual work hours are rigid, absence from work becomes the obvious adjustment margin. The borderline between voluntary and involuntary sickness absence is fuzzy, however, and it is probably not very meaningful to delve into where this line exactly should be drawn. Be that as it may, it is clear from a growing number of empirical studies that economic incentives matter for sickness absence: the lower the cost of missing work, the more likely that the worker is on sick leave.

Sickness, be it serious or trivial, is of course not something that exclusively hits employed workers. Unemployed individuals as well as nonparticipants are also prone to random changes in health or preferences for leisure. This raises intriguing issues for public social insurance policies. What are the labor market effects of changes in sickness and unemployment benefits and what is the best benefit structure from a welfare perspective? These are the issues analyzed in this paper. The purpose is to develop a framework suitable to analyze sickness absence as well as unemployment in a coherent and unified fashion.

The reason for proposing a unified analysis of sickness absence and unemployment is the recognition of potentially important interdependencies between social insurance policies in the two areas. Sickness benefits may affect the rewards from employment relative to unemployment and thus influence individual transitions between those labor force states. Unemployment benefits will also influence the relative rewards of employment and unemployment and this may in turn affect the employed worker's absence behavior if the risk of job loss depends on absence status. Moreover, it is likely that the unemployed worker's incentives to engage in active job search is affected by the 
economic consequences he would face if he decided to report sick and unable to meet the search requirements for unemployment benefit receipt. Indeed, policy discussions in several countries, including Sweden and the Netherlands, have emphasized that the flows between unemployment and reported sickness may be quantitatively important and fiscally costly.

Although government social insurance policies concerning sickness and unemployment differ across countries, there are some common characteristics. Almost all developed countries have public unemployment insurance systems where benefit levels (or replacement rates) are regulated by government policies. Sickness insurance is also generally subject to government regulations, albeit with substantial differences across countries. The paper focuses on a stylized system where the government has three policy instruments at its disposal, viz. sickness benefits available for employed workers on sick leave, unemployment benefits targeted at nonemployed job searchers, and sickness assistance intended for nonemployed individuals who report sick.

We consider an economy where chance and choice trigger individual transitions between labor market states. Chance appears as exogenous shocks to health (sickness) as well as job findings and job separations. Choice enters in the form of individual dichotomous decisions on whether to work or not (if the individual is employed) and whether to search or not (if the individual is nonemployed). Sickness strikes as stochastic shocks to the individual's utility function and affects the disutility of work as well as the disutility of job search. New realizations of sickness induce the individual to consider whether or not a transition to a new labor market state is optimal. For example, a person who is currently working may find it optimal to call in sick for sufficiently adverse shocks. Sickness thus interacts with the worker's labor supply decision and also with the nonemployed worker's search decision; a person searching for work may prefer not to search if the cost of searching is amplified by illness.

The analysis begins by considering individual optimization and proceeds to a characterization of a steady state labor market equilibrium where individuals are allocated across four different states: work, sick leave, unemployment and nonparticipation. Individuals at work or on sick leave are 
referred to as employed; individuals that are unemployed or nonparticipants are nonemployed. ${ }^{1}$ The key difference between unemployment and nonparticipation is that the probability of job finding is higher when unemployed. This distinction is in line with the usual definitions in labor force surveys where some search effort is a prerequisite for being classified as unemployed. It is also in line with empirical results showing higher job finding rates from unemployment than from nonparticipation (cf. Flinn and Heckman, 1983).

Section 2 of the paper gives some basic facts about sickness absence, policies concerning sickness absence and related literature. Section 3 presents the model and derives a number of comparative statics predictions regarding the effects of non-work benefits. These predictions concern individual decisions on sickness reporting and search as well as aggregate labor market outcomes. The analysis verifies policy interdependencies of the form alluded to in the discussion above; policies targeted at the unemployed affect sickness behavior among the employed and vice versa. For example, higher sickness benefits for employees will unambiguously increase unemployment although it may also increase total employment. Higher unemployment benefits will increase the fraction of employees on sick leave whereas the effect on the total number of sick absentees is ambiguous. The precise effects often depend on whether or not absence is associated with an excess risk of job loss.

Section 4 turns to a normative analysis of the socially optimal benefit structure. With risk-averse individuals, there is a case for insurance against income loss but the optimal level of benefits may conceivably differ depending on which labor force state that is occupied. In general, the optimal policy involves benefit differentiation across states of non-work since the behavioral responses depend on the type of benefit change that is considered. ${ }^{2}$ To the extent that job search can be monitored, there is a case for rewarding active search; unemployment benefits should then be higher than sickness assistance.

\footnotetext{
${ }^{1}$ We refer to all individuals as 'workers', irrespective of their labor market states. Since all individuals are ex ante identical, they are all potential workers.

${ }^{2}$ This claim contrasts with a common proposal to equalize benefits across states of non-work (see e.g. Lindbeck et al, 1994).
} 


\section{Sickness Absence: Facts and Findings}

\subsection{Sickness Absence}

Sickness absence among employees varies substantially across countries. Data from European labor force surveys show that absence rates around the turn of the century were particularly high in Sweden, Norway and the Netherlands (Nyman et al, 2002). In those countries, around 4 percent of the employed workers reported sickness absence exceeding one week. These numbers were about twice as high as absence rates in several other European countries. The international comparison in Barmby et al (2002) showed that absence hours relative to contractual hours hovered between 2 and 6 percent during the 1990s. Data from Statistics Norway show that Norwegian sickness absence over the period 2000-2003 has reached 7-8 percent of contractual hours.

The prevalence of sickness reporting among unemployed individuals is less well documented in the data. There is some Swedish evidence that there is an overrepresentation of unemployed individuals among recipients of sickness insurance benefits. Larsson (2004) documents that the probability of reporting sick is substantially higher among unemployed insured individuals than among insured individuals in general. Moreover, the duration of sickness benefit receipt appears to be significantly longer among the unemployed than among employees, even after controls for a number of personal characteristics (Riksförsäkringsverket, 2003).

Data on the duration of sickness spells are rarely available in a way that permits systematic comparisons over time or across countries. Swedish data indicate that the overwhelming majority of sickness spells are of short duration. In 1991, around 60 percent of the spells lasted three days or less and 80 percent lasted five days or less. Only 9 percent of the spells lasted more than two weeks. Survey data from recent years confirm that this pattern still holds. The picture looks very different, however, if one looks at spells in progress as opposed to all (completed) spells. In December 1991, around 77 percent of spells in progress had lasted 30 days or more whereas the fraction 
of long spells (30 days or more) accounted for only 5 percent of the flow. ${ }^{3}$ Most new spells of sickness thus last for just a few days but long-term sickness accounts for a substantial fraction of total sickness absence observed at a point in time.

\subsection{Sickness Insurance}

The first forms of sickness insurance were organized by voluntary organizations, including trade unions. Compulsory sickness insurance was instituted in most OECD countries during the 20th century; see Kangas (1991) for an overview. These systems vary substantially along a number of dimensions such as length of waiting period (if any) before compensation is paid out, statutory replacement rates, caps on benefits levels, time limits, requirements concerning medical certification, the extent of employer-provided sick-pay, the prevalence of collective agreements on sickness benefits, and the treatment of unemployed individuals. ${ }^{4}$ Suffice it here to note that replacement rates in sickness insurance typically differ between employed and unemployed individuals. Sickness benefits for employees often replace a (very) high fraction of income, sometimes even 100 percent if supplementary negotiated benefits are included. Sickness benefits available for unemployed persons are typically lower, often coinciding with the benefit levels provided by unemployment insurance. ${ }^{5}$

Real-world sickness insurance schemes involve various measures to mitigate moral hazard problems. Rules concerning medical certification as well

\footnotetext{
${ }^{3}$ The introduction (in 1992) of employer-provided sick pay for the first weeks of sickness has made it difficult to obtain consistent Swedish time series on sickness absence and its duration structure. The figures reported in the text are obtained from the National Social Insurance Board.

${ }^{4}$ Two useful sources of information are Werkdocument No 286 from the Dutch Ministry of Social Affairs and Employment and RFV ANALYSERAR 2003:16 from the (Swedish) National Social Insurance Board.

${ }^{5}$ There are also examples of systems where compensation from sickness insurance available for the unemployed is higher than compensation from unemployment insurance. This was true for Sweden before 1 July 2003, albeit only for workers with above-average earnings. See Larsson (2002).
} 
as monitoring by employers and/or insurance providers are obvious ways to prevent excessive use of sickness insurance when replacement rates are high. However, since sickness to a large extent is private information to the individual worker, there is little doubt that the individual has considerable influence over his absence decisions.

\subsection{Related Literature}

Research by economists on sickness absence has almost exclusively been empirical. Brown and Sessions (1996) provide a recent survey of the literature. There is an increasing amount of evidence that economic incentives matter for absence behavior; the lower the cost of missing work, the more likely that the worker is on sick leave. This strand of empirical literature includes papers by Allen (1981), Barmby et al (1991), Broström et al (2004), Johansson and Palme (1996, 2002), Henrekson and Persson (2004) and others.

The incentive system pertaining to sickness absence may also depend on employment protection legislation. Ichino and Riphahn (2003, 2004) argue that stringent employment protection may induce higher absenteeism by reducing the risk of being fired due to absence from work. Indeed, their empirical case studies based on data from Germany and Italy support their hypotheses.

Data from some countries, such as Norway and Sweden, suggest that sickness absence is strongly pro-cyclical. The precise reasons for this pattern are not well understood, however. One hypothesis emphasizes behavioral effects, arguing that workers fear job loss more when labor markets are slack and that they perceive sickness absence to be associated with higher risk of job loss. Another hypothesis emphasizes selection effects; the tighter the labor market, the higher the fraction of relatively more sickness-prone workers in the labor force. The relative importance of behavioral and selection effects remains an open issue. Several recent studies have provided evidence confirming behavioral effects (Hesselius, 2003; Askildsen et al, 2002; and Arai and Skogman Thoursie, 2001).

Theoretical work on sickness absence is relatively rare. The survey by 
Brown and Sessions (1996) discusses mainly some versions of the static neoclassical labor supply model. Other authors have emphasized labor demand considerations; Ehrenberg (1970) is a seminal paper in this regard. More recent contributions include, among others, Barmby et al (1994) who propose an efficiency wage model where firms use wage adjustment as a means to influence absence.

The present paper ignores firm behavior and focuses on the supply side. The approach is akin to a class of multistate models of labor force dynamics where Toikka (1976) is a seminal paper and other contributions include Flinn and Heckman (1982) as well as Burdett et al (1984). These papers consider individual search and labor supply decisions in stochastic environments, allowing for nonparticipation as a distinct state in addition to employment and unemployment. The value of nonmarket activity is taken as a random variable and individuals choose nonparticipation for sufficiently favorable realizations of nonmarket productivity. The more recent contribution by Garibaldi and Wasmer (2001) takes this approach one step further by incorporating endogenous wage determination.

It lies close at hand to incorporate sickness into nonparticipation; indeed, this seems to be the view taken in some of the earlier papers. The drawback of this approach is that it provides a highly inaccurate picture of sickness absence among employees. A nonparticipant contemplating labor market entry must compare the benefits of entry to the costs of search, recognizing that job offers are random rather than certain. By contrast, an employed worker on sick leave faces no search costs (unless he contemplates quitting to a new employer) and the consequences of returning to work are predictable. It is difficult to imagine how one could analyze sickness absence policies without explicit treatment of sickness absence as a distinct labor force state.

This paper focuses almost exclusively on the effects of non-work benefits. However, the framework can also be used to shed light on other issues, such as how labor market conditions and employment protection rules affect sickness absence. In fact, the analysis of non-work benefits reveals that employment protection rules may have important consequences for how benefits affect labor market outcomes. 


\section{The Model}

\subsection{Overview}

We start by a brief overview of the basic framework. There is a fixed number of individuals who can occupy one of four mutually exclusive states, viz. work, sickness absence, unemployment and nonparticipation. Work and sick leave represent employment, whereas unemployment and nonparticipation represent nonemployment. Each state is associated with a particular present discounted value of future income (utility). This value depends on income in the current state as well as incomes in all other potential states since choice and chance induce movements across states.

Employed workers are subject to a risk of job loss that may or may not differ between individuals at work and workers on sick leave. In general, there is a presumption that absence is associated with an excess layoff (or firing) risk. The state-specific firing risks are exogenous to the worker but the expected firing probability is endogenous as a result of the worker's absence decision. The expected firing probability corresponds to the fraction of employed workers that enter nonemployment in each period.

The probability that a nonemployed worker finds a job is higher if he actively searches as unemployed than if he rejects search and prefers nonparticipation. These state-specific job finding (hiring) probabilities are exogenous to the worker but the expected job finding probability is endogenous as a result of the worker's decision whether to search or not to search. The expected hiring probability corresponds to the fraction of nonemployed individuals hired in every period.

Individuals are exposed to random sickness shocks that affect the disutility of work and search. Optimal behavior is characterized by cut-off values for sickness. The employed worker prefers absence rather than work for sufficiently severe sickness; analogously, the nonemployed individual prefers nonparticipation to costly search for sufficiently severe realizations of sickness. These reservation values of sickness generally differ between employed and nonemployed individuals and depend on benefits and other parameters 
of the model.

To sketch the workings of the model, consider a rise in sickness benefits for employed workers. This makes the employed worker more prone to choose absence and causes an increase in the sickness absence rate, i.e., the fraction of employees on sick leave. However, there will also be effects on hirings and firings. Higher sickness benefits raise the value of employment relative to unemployment and makes the nonemployed worker more inclined to engage in active search. The expected hiring rate increases which in turns tends to increase employment. Higher sickness benefits will also increase the expected firing rate if absence is associated with an excess firing risk; this tends to reduce employment.

Consider as a second example the implications of higher unemployment benefits. This experiment presupposes that it is possible to target benefits at those engaged in active search. Higher unemployment benefits encourage search among the nonemployed and this raises the expected hiring rate. Both unemployment and employment tend to increase. Higher unemployment benefits may however also make the employed worker more absence-prone since the costs of job loss have fallen; this raises the expected firing rate and the outflow from employment to nonemployment.

The firms' decisions affect the probability of job loss as well as the probability of job finding but these decisions are taken as exogenous. We confine the analysis to individual adjustments along the extensive margins: the employed worker chooses between work and absence, the nonemployed between search as unemployed and nonparticipation without search. A richer analysis would incorporate the intensive margins (hours of work and hours of search) but the mechanisms identified by the simpler approach would still be present.

\subsection{Individual Preferences}

The number of individuals is normalized to unity. Individuals are all homogenous ex ante, i.e., before they have been allocated to a particular labor market state and before they have been hit by shocks to their utility functions. As already stated, there are four potential states $(j)$, viz. work $(w)$, 
sickness absence (or sick leave, $s$ ), unemployment $(u$ ), and nonparticipation $(n)$. As in conventional labor force surveys, work and sick leave represent employment, whereas unemployment and nonparticipation are referred to as nonemployment.

The individual utility function takes the general quasi-linear form

$$
v^{j}=\ln C^{j}-a^{j} \theta
$$

where $C^{j}$ is consumption, $a^{j}$ a positive parameter, and $\theta$ a stochastic utility shifter that is increasing in sickness. ${ }^{6}$ Successive $\theta$ are independently and identically distributed random variables drawn from a known distribution $F(\theta)$ with support $[0, K]$ and density $f(\theta)$. Consumption is equal to aftertax income in every period. Consumption while at work (wage income) is given as $C^{w}=Y$; work-hours are taken as fixed so $Y$ is a constant. The individual is entitled to non-work benefits when he does not work; the levels of these benefits may differ across the three states of non-work. An employed worker who is absent from work receives sickness benefits (sickpay), $C^{s}=$ $B^{s}$; an unemployed person receives unemployment benefits, $C^{u}=B^{u}$; and nonparticipants may receive what is referred to as sickness assistance, $C^{n}=$ $B^{n}$ Lower-case letters denote the natural logarithms of (after-tax) incomes in the four states, i.e., $y=\ln Y$ and $b^{j}=\ln B^{j}$.

The feasibility of differentiating between unemployment benefits to the unemployed and sickness assistance to nonparticipants depends on whether or not search effort can be monitored by government policy. Imperfect monitoring of search behavior among benefit recipients is a typical feature of existing unemployment insurance schemes. We do not introduce an explicit model of monitoring (as in Boone et al, 2002), but confine the analysis to two polar cases: the government can either perfectly monitor search or it cannot monitor search at all. Benefit differentiation between the unemployed and the nonparticipants is feasible in the first case but impossible in the second case.

\footnotetext{
${ }^{6}$ The comparative statics results are identical for a utility function that is linear in consumption/income. The normative analysis of optimal insurance requires risk aversion, however.
} 
The parameter $a^{j}$ is normalized to unity for "inactive" individuals, i.e., the sickness absentees and the nonparticipants. For individuals at work and for those who are unemployed, $a^{j}$ is assumed to be greater than unity. That is, $a^{j}=1$ for $j=s, n$, and $a^{j}>1$ for $j=w, u$. From now on we drop the superscript and take $a$ as strictly greater than one, i.e., $a>1$. The assumptions concerning $a$ capture the idea that the disutility of work or search is increasing in sickness. ${ }^{7}$

\subsection{Value Functions and Decision Rules}

The model is set in discrete time where future sickness status is uncertain. Tomorrow is another day and each morning involves a draw from $F(\theta)$. If the worker is employed there is some risk of job loss and if the worker is nonemployed there is some chance of job finding. The probability of job loss may differ between workers at work and workers on sick leave. Let $\phi^{w}$ denote the job loss probability for a person at work and $\phi^{s}$ the corresponding probability for a person on sick leave. Assume that work can never be more risky than sick leave, i.e., $\phi^{w} \leq \phi^{s}$. A natural benchmark case involves equal separation risks, $\phi^{w}=\phi^{s}=\phi$, which may correspond to a stringent employment protection legislation. The probability of job finding is denoted $\alpha^{u}$ if the individual is unemployed (searching) and as $\alpha^{n}$ if the individual is not participating in the labor force (not searching). We assume $\alpha^{u}>\alpha^{n}$ where $\alpha^{n} \geq 0$. $^{8}$

The parameters of the model are such that employment is always preferred to nonemployment, a viability condition that puts restrictions on the transition probabilities and the benefit structure. Job offers are thus always accepted by nonemployed individuals. The key decision for an employed worker is whether to choose work or sick leave. The analogous decision for a nonemployed worker is whether to search or not to search, i.e., whether to

\footnotetext{
${ }^{7}$ To illustrate the general idea, suppose that the utility function takes the form $v^{j}=$ $\ln C^{j}-\left(1+I^{j}\right) \theta$, where $I^{j}$ represents effort devoted to work or to search. We then have $I^{j}=0(a=1)$ for $j=s, n$ and $I^{j}>0(a>1)$ for $j=w, u$.

${ }^{8} \mathrm{Job}$ finding without search $\left(\alpha^{n}>0\right)$ is possible because employers may initiate contacts with workers.
} 
choose unemployment or nonparticipation.

With these assumptions we are ready to consider the value functions. Let $W(\theta)$ denote the expected present value of being at work, $S(\theta)$ the value of being on sick leave, $U(\theta)$ the value of being unemployed, and $N(\theta)$ the value of being a nonparticipant. These present values are computed after a particular realization of $\theta$ and involves optimal behavior with respect to future shocks. The value functions are written as follows:

$$
\begin{aligned}
W(\theta)= & {\left[y-a \theta+\int_{0}^{K} \phi^{w}\{\max [U(x), N(x)]\} d F(x)\right.} \\
& \left.+\int_{0}^{K}\left(1-\phi^{w}\right)\{\max [W(x), S(x)]\} d F(x)\right] \frac{1}{1+r} \\
S(\theta)= & {\left[b^{s}-\theta+\int_{0}^{K} \phi^{s}\{\max [U(x), N(x)]\} d F(x)\right.} \\
& \left.+\int_{0}^{K}\left(1-\phi^{s}\right)\{\max [W(x), S(x)]\} d F(x)\right] \frac{1}{1+r} \\
U(\theta)= & {\left[b^{u}-a \theta+\int_{0}^{K} \alpha^{u}\{\max [W(x), S(x)]\} d F(x)\right.} \\
& \left.+\int_{0}^{K}\left(1-\alpha^{u}\right)\{\max [U(x), N(x)]\} d F(x)\right] \frac{1}{1+r} \\
N(\theta)= & {\left[b^{n}-\theta+\int_{0}^{K} \alpha^{n}\{\max [W(x), S(x)]\} d F(x)\right.} \\
& \left.+\int_{0}^{K}\left(1-\alpha^{n}\right)\{\max [U(x), N(x)]\} d F(x)\right] \frac{1}{1+r}
\end{aligned}
$$

The present value of being employed and working involves a flow return given by $y-a \theta$ as well as changes in utility caused by sickness and labor market shocks. The probability of job loss is $\phi^{w}$ and the probability of retaining the job is $1-\phi^{w}$. If the worker is laid off he decides whether to choose unemployment or nonparticipation, i.e., he takes max $[U(x), N(x)]$. If the job is retained the choice is between work and sick leave and the worker 
thus takes max $[W(x), S(x)]$. End-of-period discounting is applied at the rate $r>0$. Analogous interpretations hold for the other value functions.

The decision rules are such that sufficiently serious sickness makes the worker more inclined to prefer inactivity to activity, i.e., sick-leave is preferred to work and nonparticipation is preferred to unemployment. Consider an individual at work who observes a new value of $\theta$ and decides to remain at work as long as $\theta$ does not exceed a critical value, $Q$. That is, work is chosen for $\theta \leq Q$ and sickness absence for $\theta>Q$. Analogous rules apply to nonemployed individuals. Let $R$ denote the critical value of sickness for a nonemployed person. Search unemployment is chosen for $\theta \leq R$ and nonparticipation for $\theta>R$. A reservation sickness strategy is optimal for the employed worker when $W(\theta) \geq S(\theta)$ for $\theta \leq Q$, and $W(\theta)<S(\theta)$ for $\theta>Q$. Note that both $W(\cdot)$ and $S(\cdot)$ are decreasing in $\theta$, with $W^{\prime}(\theta)<S^{\prime}(\theta)$ :

$$
W^{\prime}(\theta)=-\frac{a}{1+r}, \quad S^{\prime}(\theta)=-\frac{1}{1+r}
$$

which guarantees the optimality of the reservation sickness rule since $a>1$. For a nonemployed person, the optimality of the reservation sickness rule requires that $U(\theta) \geq N(\theta)$ for $\theta \leq R$, and $U(\theta)<N(\theta)$ for $\theta>R$. $U(\cdot)$ and $N(\cdot)$ are both decreasing in $\theta$, with slopes:

$$
U^{\prime}(\theta)=-\frac{a}{1+r}, \quad N^{\prime}(\theta)=-\frac{1}{1+r}
$$

so the inequality $U^{\prime}(\theta)<N^{\prime}(\theta)$ obviously holds. The value functions are illustrated in Figure 1.

Given the existence of unique reservation values, the probability of reporting sick is $1-F(Q)$ if the worker is employed and $1-F(R)$ if he is nonemployed. The probability of reporting sick is obviously decreasing in the reservation values.

The reservation sickness conditions imply that we can define the following maximum value functions for employment and nonemployment:

$$
M^{e} \equiv \int_{0}^{Q} W(x) d F(x)+\int_{Q}^{K} S(x) d F(x)
$$




$$
M^{o} \equiv \int_{0}^{R} U(x) d F(x)+\int_{R}^{K} N(x) d F(x)
$$

where $M^{e}$ pertains to employment (work and sick leave) and $M^{o}$ to nonemployment (unemployment and nonparticipation). $M^{e}$ and $M^{o}$ are ex ante expected present values of employment and nonemployment in the sense that they correspond to present values before the veil of ignorance concerning $\theta$ is lifted, given that optimal decision rules are followed in the future. By virtue of individual optimization, these values are (locally) independent of the relevant reservation values of sickness. That is,

$$
\frac{\partial M^{e}}{\partial Q}=0, \quad \frac{\partial M^{o}}{\partial R}=0
$$

as is clear from differentiation of (6) and (7) and evaluating at $Q$ and $R$, respectively.

The reservation sickness conditions can now be computed by imposing the indifference condition $W(Q)=S(Q)$ for the employed worker and the analogous condition $U(R)=N(R)$ for a worker who is not employed:

$$
\begin{gathered}
Q=\frac{y-b^{s}+\left(\phi^{s}-\phi^{w}\right)\left(M^{e}-M^{o}\right)}{a-1} \\
R=\frac{b^{u}-b^{n}+\left(\alpha^{u}-\alpha^{n}\right)\left(M^{e}-M^{o}\right)}{a-1}
\end{gathered}
$$

These expressions can also be written as

$$
\begin{gathered}
b^{s}-Q-(y-a Q)=\left(\phi^{s}-\phi^{w}\right)\left(M^{e}-M^{o}\right) \\
b^{n}-R-\left(b^{u}-a R\right)=\left(\alpha^{u}-\alpha^{n}\right)\left(M^{e}-M^{o}\right)
\end{gathered}
$$

where the left-hand sides capture the immediate gain of choosing sick leave relative to work, or nonparticipation relative to search, and the right-hand sides represent the associated costs. The costs are in terms of foregone employment opportunities; the employed worker may run an excess risk of being fired when choosing sick leave and the nonemployed worker will be less likely to find a job when choosing not to search. The gains and costs are equal at the points of indifference between work and sick leave (search and nonparticipation). 


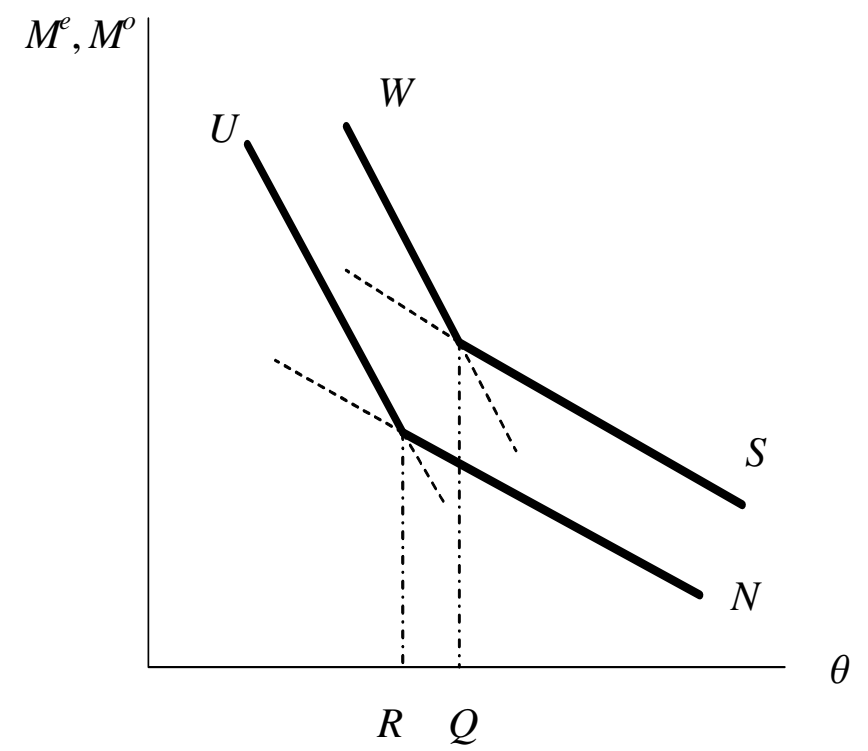

Figure 1: Value functions.

The reservation values are determined by four factors. First, the flow utility difference between activity and inactivity clearly matters; the relevant variable is $y-b^{s}$ for the employed worker and $b^{u}-b^{n}$ for a worker who is not employed. The higher the relative gain of being active, the higher the reservation value (and the lower the probability of reporting sick). Differences in transition probabilities also matter, i.e., $\phi^{s}-\phi^{w}$ for the employed worker and $\alpha^{u}-\alpha^{n}$ for a nonemployed worker. The higher the excess firing risk associated with absence, the lower the probability of sickness absence. And the higher the relative returns to active search, the lower the probability that a nonemployed worker reports sick. A third factor is the difference between the values of being employed and nonemployed in the future, i.e., $M^{e}-M^{o}$. Finally and trivially, the disutility of work and search, captured by the parameter $a$, matters.

An equilibrium satisfying the viability constraint $M^{e}-M^{o} \geq 0$ may imply $Q>R$ (as illustrated in Figure 1) but does not rule out $Q \leq R$. Note from (8) that positive work attendance, $F(Q)>0$, requires $y>b^{s}$ if there is no excess firing risk associated with sickness absence $\left(\phi^{s}=\phi^{w}\right)$. 
The maximum values of employment and unemployment are functions of all parameters of the problem. This generally implies that variables specific to nonemployment, such as unemployment benefits and job offer probabilities, will affect absence decisions also among employed workers (except when $\phi^{w}=$ $\left.\phi^{s}\right)$. Analogously, variables specific to employment affect search decisions among the nonemployed. Changes in benefits will have direct effects - given $M^{e}$ and $M^{o}$ - as well as indirect effects operating via changes in $M^{e}$ and $M^{o}$.

\subsection{Comparative Statics}

\subsubsection{Preliminaries}

It will be convenient to combine eqs. (2)-(7) and write the maximum value functions, $M^{e}$ and $M^{o}$, as

$$
\begin{aligned}
M^{e}= & \beta \int_{0}^{Q}\left[y-a \theta+\phi^{w} M^{o}+\left(1-\phi^{w}\right) M^{e}\right] d F(\theta)+ \\
& \beta \int_{Q}^{K}\left[b^{s}-\theta+\phi^{s} M^{o}+\left(1-\phi^{s}\right) M^{e}\right] d F(\theta) \\
M^{o}= & \beta \int_{0}^{R}\left[b^{u}-a \theta+\alpha^{u} M^{e}+\left(1-\alpha^{u}\right) M^{o}\right] d F(\theta)+ \\
& \beta \int_{R}^{K}\left[b^{n}-\theta+\alpha^{n} M^{e}+\left(1-\alpha^{n}\right) M^{o}\right] d F(\theta)
\end{aligned}
$$

where $\beta \equiv 1 /(1+r)$. These expressions can be written more compactly as

$$
\begin{aligned}
& \Psi^{e} \equiv M^{e}-\Gamma^{e}\left(M^{e}, M^{o} ; \cdot\right)=0 \\
& \Psi^{o} \equiv M^{o}-\Gamma^{o}\left(M^{e}, M^{o} ; \cdot\right)=0
\end{aligned}
$$

where $\Gamma^{e}\left(M^{e}, M^{o} ; \cdot\right)$ is the right-hand side of $(10)$ and $\Gamma^{o}\left(M^{e}, M^{o} ; \cdot\right)$ is the right-hand side of (11). Eqs. (8), (9), (12) and (13) determine $Q, R, M^{e}$ and $M^{o}$ as functions of the parameters of the problem. Since $M^{e}$ and $M^{o}$ are invariant to derivative changes of $Q$ and $R$ we can focus on eqs. (12) and (13) when examining the determinants of $M^{e}$ and $M^{o}$. Differentiation of (12) and $(13)$ yields a determinant of the form $H \equiv r(r+\tilde{\alpha}+\tilde{\phi}) /(1+r)^{2}>0$, 
where $\tilde{\alpha} \equiv \alpha^{u} F(R)+\alpha^{n}(1-F(R))$ is the expected hiring rate and $\tilde{\phi} \equiv$ $\phi^{w} F(Q)+\phi^{s}(1-F(Q))$ the expected firing rate.

Eqs. (12) and (13) can also usefully be written as asset value equations of the form:

$$
\begin{aligned}
& r M^{e}=\tilde{v}^{e}(\cdot)+\tilde{\phi}\left(M^{o}-M^{e}\right) \\
& r M^{o}=\tilde{v}^{o}(\cdot)+\tilde{\alpha}\left(M^{e}-M^{o}\right)
\end{aligned}
$$

where $\tilde{v}^{e}(\cdot)$ is the expected per-period utility if employed and $\tilde{v}^{o}(\cdot)$ the expected per-period utility if nonemployed. In particular,

$$
\begin{aligned}
& \tilde{v}^{e} \equiv F(Q)\left[y-E(\theta \mid \theta \leq Q]+(1-F(Q))\left[b^{s}-E(\theta \mid \theta>Q]\right.\right. \\
& \tilde{v}^{o} \equiv F(R)\left[b^{u}-E(\theta \mid \theta \leq R]+(1-F(R))\left[b^{n}-E(\theta \mid \theta>R]\right.\right.
\end{aligned}
$$

where $E$ stands for the expectations operator.

\subsubsection{Non-work Benefits, Absence and Search}

Consider how changes in non-work benefits affect reservation values of sickness while employed $(Q)$ and nonemployed $(R)$. Remember that the decision on $Q$ entails a decision on absence when employed whereas the decision on $R$ implies a decision whether or not to engage in job search. The government's budget restriction is ignored in this exercise; in fact, under the assumptions that we will subsequently introduce, taxes do not influence the choice of reservation values.

As noted, the effects of interest have two components, namely direct " $M$ constant" effects as well as indirect " $M$-variable" effects. Sickness benefits while employed $\left(b^{s}\right)$ affect $R$ only indirectly; analogously, unemployment benefits $\left(b^{u}\right)$ and sickness assistance $\left(b^{n}\right)$ affect $Q$ only indirectly. The three cases 
where both direct and indirect effects are present are as follows:

$$
\begin{aligned}
& \frac{d Q}{d b^{s}}=-\frac{1}{a-1}+\frac{1}{a-1}\left(\phi^{s}-\phi^{w}\right)\left[\frac{\partial\left(M^{e}-M^{o}\right)}{\partial b^{s}}\right] \\
& \frac{d R}{d b^{u}}=\frac{1}{a-1}+\frac{1}{a-1}\left(\alpha^{u}-\alpha^{n}\right)\left[\frac{\partial\left(M^{e}-M^{o}\right)}{\partial b^{u}}\right] \\
& \frac{d R}{d b^{n}}=-\frac{1}{a-1}+\frac{1}{a-1}\left(\alpha^{u}-\alpha^{n}\right)\left[\frac{\partial\left(M^{e}-M^{o}\right)}{\partial b^{n}}\right]
\end{aligned}
$$

The first terms are obtained from partial differentiation of the right-hand sides of (8) and (9) with respect to $b^{j}$ and can be thought of as a substitution effect. It can be produced by a change in benefits accompanied by compensating income variations to employed and nonemployed workers so as to keep both $M^{e}$ and $M^{o}$ constant (or the difference between the two). The substitution effect captures the immediate incentive to prefer a state that has become more attractive.

The $M$-adjustments can be thought of as wealth changes arising from benefit increases. As is clear from (18), the bigger a positive impact of sickness benefits on the difference between $M^{e}$ and $M^{o}$, the less likely that absence increases. This wealth effect on $Q$ vanishes when separation risks are equal. Analogously, what matters for search decisions is the relative impact on $M^{e}$ and $M^{o}$. The bigger the impact on $M^{e}$, the more likely that the worker chooses search ("high" $R$ ) since active search increases the probability of job finding.

Straightforward calculations yield the following effects on $M^{e}-M^{o}$ :

$$
\begin{aligned}
& \frac{\partial\left(M^{e}-M^{o}\right)}{\partial b^{s}}=\frac{1-F(Q)}{\tilde{\alpha}+\tilde{\phi}+r}>0 \\
& \frac{\partial\left(M^{e}-M^{o}\right)}{\partial b^{u}}=-\frac{F(R)}{\tilde{\alpha}+\tilde{\phi}+r}<0 \\
& \frac{\partial\left(M^{e}-M^{o}\right)}{\partial b^{n}}=-\frac{1-F(R)}{\tilde{\alpha}+\tilde{\phi}+r}<0
\end{aligned}
$$

Higher sick pay to an employed worker is of immediate value to such an individual but of only future value to a nonemployed individual. Hence 
$\partial\left(M^{e}-M^{o}\right) / \partial b^{s}>0$. Analogously, higher unemployment benefits or sickness assistance are of immediate value only for the nonemployed which explains the negative signs in (22) and (23). ${ }^{9}$

The comparative statics results concerning $Q$ and $R$ are displayed in Table 1. We also include the effect on the expected hiring probability, $\tilde{\alpha}$, and the expected firing probability, $\tilde{\phi}$; note that the former is rising in $R$, $d \tilde{\alpha} / d R=\left(\alpha^{u}-\alpha^{n}\right) f(R)>0$, whereas the latter is nonincreasing in $Q$, $d \tilde{\phi}=\left(\phi^{w}-\phi^{s}\right) f(Q) \leq 0$.

The direct (substitution) effects are reinforced by the indirect (wealth) effects in one case and counteracted in two cases. First, a rise in $b^{n}$ has a direct negative effect on $R$, reducing the propensity to search, as well as a reinforcing effect via wealth changes; the value of nonemployment increases more than the value of employment, $\partial\left(M^{e}-M^{o}\right) / \partial b^{n}<0$. Second, a rise in $b^{s}$ has a direct negative effect on $Q$ that tend to increase sick leave. In addition, there is a positive effect on $Q$ via the wealth effects since $\partial\left(M^{e}-M^{o}\right) / \partial b^{s}>0$; higher sickpay raises the value of employment relative to nonemployment and this makes the worker less inclined to report sick when absence is associated with an excess layoff risk. The third case pertains to unemployment benefits that have a direct positive effect on $R$, making the worker more prone to search. There is in addition also an indirect negative effect caused by the fact that the value of employment falls relative to the value of nonemployment, i.e., $\partial\left(M^{e}-M^{o}\right) / \partial b^{u}<0$. The calculations reveal that the sign-predictions are unambiguous even in the two cases with conflicting direct and indirect effects. The direct effects dominate the indirect effects. ${ }^{10}$

\footnotetext{
${ }^{9}$ To understand expressions (21) - (23), it is useful to look at the effects on $M^{e}$ and $M^{o}$ separately. For example, the effect on $M^{e}$ of higher sickness benefits is given by $\partial M^{e} / \partial b^{s}=[1-F(Q)](1 / r)[(\tilde{\alpha}+r) /(\tilde{\alpha}+\tilde{\phi}+r)]$. In the limiting case when employment is an absorbing state $\left(\tilde{\phi}\right.$ approaches zero) we have $\partial M^{e} / \partial b^{s}=[1-F(Q)] / r$, which is the present value effect of higher sickness benefits when there is no risk of job loss.

${ }^{10} \mathrm{As}$ is clear from (18) and (19), unambiguous sign-predictions require $\left(\phi^{s}-\right.$ $\left.\phi^{w}\right)\left(\partial M^{e} / \partial b^{s}-\partial M^{o} / \partial b^{s}\right)<1$ and $\left(\alpha^{u}-\alpha^{n}\right)\left(\partial M^{e} / \partial b^{u}-\partial M^{o} / \partial b^{u}\right)>-1$. These inequalities are satisfied.
} 
Table 1. Effects of non-work benefits on reservation sickness, hirings and firings.

\begin{tabular}{c|cccc}
\hline \hline & $R$ & $Q$ & $\tilde{\alpha}$ & $\tilde{\phi}$ \\
\hline$b^{s}$ & + & - & + & $+(0)$ \\
$b^{u}$ & + & $-(0)$ & + & $+(0)$ \\
$b^{n}$ & - & $-(0)$ & - & $+(0)$ \\
$b^{u}=b^{n}$ & - & $-(0)$ & - & $+(0)$ \\
\hline \hline
\end{tabular}

Note: Zeros in parentheses correspond to the case where $\phi^{w}=\phi^{s}$. The last line shows the effects of a rise in both types of nonemployment benefits.

Higher sick-pay for employed workers increases $R$, thus making nonemployed workers less inclined to report sick and more inclined to search as unemployed. The effect is analogous to the "entitlement effect" discussed in the literature on unemployment insurance. ${ }^{11}$ Higher sick-pay for employees increases the value of employment relative to nonemployment, thus making the nonemployed worker more prone to choose active search as unemployed since unemployment serves as an entry port to employment.

Higher unemployment benefits or sickness assistance will reduce $Q$, implying a higher probability of sickness reporting, provided that sick leave carries an excess firing risk. The intuition is not difficult: higher nonemployment benefits make nonemployment relatively more attractive and weakens the incentive to prevent a job loss by being present at work.

The final row in Table 1 shows the effects of a simultaneous increase in unemployment benefits and sickness assistance. The effect on $Q$ is obvious given the earlier results. The effect on $R$ is less obvious given that $\partial R / \partial b^{u}>$ 0 whereas $\partial R / \partial b^{n}<0$. However, the net effect of simultaneous benefit increases is negative. This follows from the fact that higher nonemployment benefits lead to a fall in the present value difference between employment and nonemployment, i.e., $M^{e}-M^{o}$. As is obvious from (9), the direct effect on $R$ of a general increase in nonemployment benefits is zero so the total effect is entirely driven by the indirect wealth effect.

Summarizing the results in words, we have:

\footnotetext{
${ }^{11}$ The seminal paper is Mortensen (1977).
} 
Proposition 1 (i) Higher sickness benefits will increase the probability of reporting sick if the worker is employed and reduce the probability of sick reporting if the worker is nonemployed. (ii) Higher unemployment benefits will reduce the nonemployed worker's probability of reporting sick. (iii) Higher sickness assistance, as well as a uniform increase in unemployment benefits and sickness assistance, will increase the nonemployed worker's probability of reporting sick. (iv) Higher unemployment benefits as well as higher sickness assistance will increase the employed worker's probability of reporting sick if $\phi^{s}>\phi^{w}$; there will be no effect if $\phi^{s}=\phi^{w}$.

Proof Differentiate eqs. (8) and (9) while recognizing eqs. (21) -(23) and the facts that $\tilde{\alpha}=F(R) \alpha^{u}+\left(1-F(R) \alpha^{n}\right.$ is increasing in $R$ and $\tilde{\phi}=$ $F(Q) \phi^{w}+(1-F(Q)) \phi^{s}$ is non-increasing in $Q$.

\subsubsection{Flow Equilibrium}

The individual worker's choice of reservation sickness affects the transition rates between the four labor market states and the expected fractions of time spent in those states. We now take a step towards an aggregate analysis by considering the flow equilibrium of a labor market with a large number of individuals. The equations for the flow equilibrium are given in Appendix A. The solutions - including total employment, $e=w+s$, the sickness absence rate, $s^{r}=s / e$ and the unemployment rate, $u^{r}=u /(u+e)-$ are given by eqs. (24)-(30). Note that $e$ can be interpreted as the unconditional probability that an individual is employed as well as the expected proportion of employed individuals. Analogous interpretations hold for the other states. The effects of non-work benefits operate through the two reservation sickness variables, $Q$ and $R$, where these variables affect total employment via hirings and firings since $\tilde{\alpha}=\tilde{\alpha}(R)$ and $\tilde{\phi}=\tilde{\phi}(Q)$. 


$$
\begin{aligned}
e & =\tilde{\alpha} /(\tilde{\alpha}+\tilde{\phi}) \\
w & =\tilde{\alpha} F(Q) /(\tilde{\alpha}+\tilde{\phi})=F(Q) e \\
s & =\tilde{\alpha}[1-F(Q)] /(\tilde{\alpha}+\tilde{\phi})=[1-F(Q)] e \\
u & =\tilde{\phi} F(R) /(\tilde{\alpha}+\tilde{\phi})=F(R)(1-e) \\
n & =\tilde{\phi}[1-F(R)] /(\tilde{\alpha}+\tilde{\phi})=[1-F(R)](1-e) \\
u^{r} & =\frac{\tilde{\phi} F(R)}{\tilde{\alpha}+\tilde{\phi} F(R)}=\frac{F(R)(1-e)}{F(R)(1-e)+e} \\
s^{r} & =1-F(Q)
\end{aligned}
$$

It is useful to begin by considering the effects of changes in $Q$ and $R$, remembering that a rise in either of these variables implies a rise in labor market activity, either as work or as search. Note that $Q$ and $R$ in general affect the magnitude of all stocks. However, the sickness absence rate depends on $Q$ but is independent of $R$. The unemployment rate, as conventionally measured, depends on both $R$ and $Q$ but reduces to $u^{r}=\phi /\left(\phi+\alpha^{u}\right)$ in the special case where $\phi^{s}=\phi^{w}=\phi$ and $\alpha^{n}=0$.

By differentiating eqs. (24)-(30) with respect to $Q$ and $R$ we get the signs as given by the top panel in Table 2 . Results for the special case with state-independent firing risks, $\phi^{w}=\phi^{s}$, are given in parentheses. A rise in $Q$ obviously increases the number of people at work but will also increase total employment and reduce unemployment provided that absence entails an excess firing risk; a higher $Q$ implies less outflow from employment to unemployment. A rise in $R$ increases total employment as well as its components work and sick-leave. This positive employment effect is driven by the fact that a rise in $R$ is equivalent to a rise in search effort on the extensive margin.

Three signs in the two top rows of Table 2 may not be immediately obvious by simple inspection of Table 1 and the relevant equations for the state probabilities. A rise in $Q$ reduces the absence rate but increases total employment through a lower firing rate. It is straightforward to verify that the net 
impact on the number of sick absentees is negative; the direct effect via the absence rate dominates the indirect effect via the firing rate. Analogously, a rise in $R$ increases the fraction of searching nonemployed workers but reduces nonemployment (increases employment) via a higher hiring rate. The net impact on the number of unemployed (and the unemployment rate) is positive so the direct effect via the fraction of searching nonemployed dominates the partly offsetting effect via the hiring rate.

Table 2. Labor force effects of non-work benefits.

\begin{tabular}{c|c|c|c|c|c|c|c}
\hline \hline & $e$ & $w$ & $s$ & $u$ & $n$ & $u^{r}$ & $s^{r}$ \\
\hline \hline$Q$ & $+(0)$ & + & - & $-(0)$ & $-(0)$ & $-(0)$ & - \\
$R$ & + & + & + & + & - & + & 0 \\
\hline$b^{s}$ & $?(+)$ & $?[-]$ & $?(+)$ & + & $?(-)$ & + & + \\
$b^{u}$ & $?(+)$ & $?(+)$ & $?(+)$ & + & $?(-)$ & + & $+(0)$ \\
$b^{n}$ & - & - & $?(-)$ & $?(-)$ & + & $?(-)$ & $+(0)$ \\
$b^{u}=b^{n}$ & - & - & $?(-)$ & $?(-)$ & + & $?(-)$ & $+(0)$ \\
\hline \hline
\end{tabular}

Note: The first two lines show the effects of changes in $Q$ and $R$, the remaining lines the effects of changes in benefits that work via $Q$ and $R$. Signs in parentheses correspond to the special case $\phi^{s}=\phi^{w}$. The sign in the squared brackets is "plausible"; see Appendix B.

The lower panel of Table 2 shows how the three types of non-work benefits affect the size of the labor force categories. From eqs. (24)-(30), it is clear that one can view the effects on $w, s, u$, and $n$ as the net result of two factors, viz. how total employment (nonemployment) is affected, and how employed (nonemployed) workers are allocated between work and sick leave (unemployment and nonparticipation). We know that some policies, such as increases in sickness or unemployment benefits, in general tend to raise both hirings and firings; cf. Table 1. Since changes in employment are driven by changes in hirings and firings, it follows that sickness and unemployment benefits have generally ambiguous effects on total employment. However, only the hiring effect remains if strict employment protection legislation rules out absence-dependent firing risk; the effect on total employment is then 
positive. Higher sickness assistance to nonparticipants, or a uniform rise in nonemployment benefits, tend to reduce hirings (less incentive to search) and increase firings (less costly to be absent); the resulting effect on employment is unambiguously negative.

Sickness benefits as well as unemployment benefits have also generally ambiguous effects on the number of individuals at work. A higher fraction of the employed prefers sick leave; the sickness absence rate increases. Since the employment effect is ambiguous except in a special case, it is not clear whether the total number of individuals at work will increase or decrease. This ambiguity is somewhat surprising but it can be ruled out as implausible; see Appendix B for details.

Higher sickness benefits produce unambiguous increases in the number of unemployed individuals and also in the unemployment rate. This is the net result of three forces, namely (i) a rise in the fraction of nonemployed, $F(R)$, that pursue active search (higher $R$ ), (ii) a fall in the number of nonemployed, $1-e$, because of a rise in the hiring rate (higher $\tilde{\alpha}$ via higher $R$ ), and (iii) a rise in nonemployment due to a rise in firings (higher $\tilde{\phi}$ via lower $Q$ ). The net impact of the first two effects is positive $(\partial u / \partial R>0)$, which guarantees a positive sign even if absence carries no excess firing risk. Unemployment will also increase as a response to higher unemployment benefits; the forces are essentially the same as those mentioned above.

Higher sickness assistance to nonparticipants, as well as a uniform rise in unemployment benefits and sickness assistance, have unambiguously negative effects on the number of employees at work as well as total employment. Higher sickness assistance reduces the hiring rate (lower $R$ ) and increases the firing rate (lower $Q$ ). Nonparticipation increases whereas the effects on the number of unemployed and the unemployment rate are ambiguous except in special cases. When the firing risk is independent of absence status, it is only the negative hiring effect (via lower $R$ ) that operates and unemployment falls.

Proposition 2 summarizes the results in words. Note that the effects on the sickness absence rate is already given by proposition 1 . 
Proposition 2 General case, $\phi^{s} \geq \phi^{w}$.

(i) Higher sickness or unemployment benefits will increase the number of unemployed and the unemployment rate. (ii) Higher sickness assistance, as well as a uniform rise in unemployment benefits and sickness assistance, reduces total employment and the number of employees at work whereas nonparticipation increases.

Special case $\phi^{s}=\phi^{w}$.

(iii) Higher sickness or unemployment benefits will increase total employment and the number of sickness absentees, whereas nonparticipation falls. (iv) Higher sickness assistance, as well as a uniform increase in unemployment benefits and sickness assistance, reduces the number of people on sick leave, the number of unemployed individuals and the unemployment rate. (v) Higher unemployment benefits will increase the number of employees at work.

Proof Differentiate eqs. (24)-(30) while recognizing eqs. (8), (9) and (21)-(23) as well as the facts that $\tilde{\alpha}=F(R) \alpha^{u}+\left(1-F(R) \alpha^{n}\right.$ is increasing in $R$ and $\tilde{\phi}=F(Q) \phi^{w}+(1-F(Q)) \phi^{s}$ is non-increasing in $Q$.

This concludes the positive analysis and we turn to the welfare economics of social insurance benefits.

\section{Welfare Analysis}

\subsection{Objective Function and Budget Restriction}

To analyze the problem of choosing non-work benefits in a socially optimal fashion we need to specify the social welfare function as well as the mode of benefit financing. The general form of the social welfare function is taken to be utilitarian:

$$
\Omega=e r M^{e}+(1-e) r M^{o}
$$

where $r M^{e}$ and $r M^{o}$ are given by (14) and (15) above. To slightly simplify matters, and to allow comparisons of steady states without considering adjustment paths, we let the discount rate approach zero and obtain 
$r M^{e}=r M^{o}=r M$. The relevant objective function is thus $\Omega=r M$, which also can be written as a weighted average of per-period expected utilities: ${ }^{12}$

$$
\Omega=e \tilde{v}^{e}+(1-e) \tilde{v}^{o}
$$

We assume that benefits are financed by proportional taxation and take the after-tax replacement rates as the key policy variables. The government's budget restriction is given by

$$
w t Y^{g}=s \rho^{s} Y^{g}(1-t)+u \rho^{u} Y^{g}(1-t)+n \rho^{n} Y^{g}(1-t)
$$

where $Y^{g}$ is gross labor income, i.e., $Y=Y^{g}(1-t)$ and $\rho^{j}$ the replacement rate. The restriction can alternatively be written as:

$$
t^{\prime} \equiv \frac{t}{1-t}=(s / w) \rho^{s}+(u / w) \rho^{u}+(n / w) \rho^{n}
$$

where $t^{\prime}$ is the effective tax rate on individuals at work.

Recall that $b^{j}=\ln B^{j}$ and thus $b^{j}=\ln \rho^{j} Y^{g}(1-t)=\ln \rho^{j}+y^{g}+\ln (1-t)$, where $y^{g}=\ln Y^{g}$. It follows that the tax rate has no effect on the reservation values of sickness when employed or nonemployed. Cf. eqs. (8) and (9) and note that the direct utility differences, $y-b^{s}$ and $b^{u}-b^{n}$, are independent of the tax rate. Moreover, the indirect effects operating via the present value difference $M^{e}-M^{o}$ are also zero. This is obvious from the fact that the tax rate is uniform across the four states. This feature of the model is deliberately chosen so as to make balanced-budget analysis more tractable. ${ }^{13}$

With these assumptions we can write the social welfare function as

$$
\Omega=-\ln \left[1+t^{\prime}\left(\rho^{s}, \rho^{u}, \rho^{n}\right)\right]+e(Q, R) \hat{v}^{e}\left(Q ; \rho^{s}\right)+[1-e(Q, R)] \hat{v}^{o}\left(R ; \rho^{u}, \rho^{n}\right)
$$

\footnotetext{
${ }^{12}$ To see this, use (14) and (15) to obtain $M^{e}-M^{o}=\left(\tilde{v}^{e}-\tilde{v}^{o}\right) /(r+\tilde{\alpha}+\tilde{\phi})$. Substitute into the expressions for $r M^{e}$ and $r M^{o}$ and assume $r \rightarrow 0$.

${ }^{13}$ Note that the chosen assumptions imply that sickness absence as well as unemployment will be independent of the level of the real wage. This is arguably an attractive feature in light of the trend rise in real wages without marked trends in unemployment and absence rates.
} 
where $\hat{v}^{e}(\cdot) \equiv \tilde{v}^{e}(\cdot)-\ln (1-t)$ and $\hat{v}^{o}(\cdot) \equiv \tilde{v}^{o}(\cdot)-\ln (1-t)$ are per-period expected utilities as given by eqs. (16) and (17) except for the fact that net income $(y)$ is replaced by gross income $\left(y^{g}\right)$. The first term on the right-hand side captures the fiscal externality present in the economy. When individuals make decisions on absence or search, they do not internalize the effect on taxes. Changes in $Q$ and $R$ have no first-order effect on social welfare except for the impact on the tax rate. The envelope theorem implies that the welfare function is invariant to derivative changes of $Q$ and $R$ when these cut-off values are optimally chosen and the tax rate is constant. This also implies that changes in employment have no direct effect on social welfare as long as the tax rate is fixed. Social welfare would rise if individuals could be made slightly more willing to work and to search, respectively. ${ }^{14}$

\subsection{Welfare Maximization}

The first-order conditions for optimal non-work benefits take the form:

$$
\frac{d \Omega}{d \rho^{j}}=\frac{\partial \Omega}{\partial \rho^{j}}+\frac{d \Omega}{d t^{\prime}} \frac{d t^{\prime}}{d \rho^{j}}=0
$$

where $\rho^{j}\left(\partial \Omega / \partial \rho^{j}\right)=\partial \Omega / \partial b^{j}$. The first term captures the positive welfare effect from higher benefits, holding taxes constant. The second term represents the negative effect arising from the need to finance higher benefits by higher taxes. We have $\partial \Omega / \partial \rho^{s}=e[1-F(Q)]=s, \partial \Omega / \partial \rho^{u}=(1-e) F(R)=u$, and $\partial \Omega / \partial \rho^{n}=(1-e)[1-F(R)]=n$. Moreover, $d \Omega / d t^{\prime}=-1 /\left(1+t^{\prime}\right)$ and the impact of benefit changes on the effective tax rate is given as

$$
\frac{d t^{\prime}}{d \rho^{j}}=\frac{\partial t^{\prime}}{\partial \rho^{j}}+\rho^{s} \frac{d(s / w)}{d \rho^{j}}+\rho^{u} \frac{d(u / w)}{d \rho^{j}}+\rho^{n} \frac{d(n / w)}{d \rho^{j}}
$$

where $\partial t^{\prime} / \partial \rho^{j}$ is the direct tax effect, absent any behavioral responses from changes in benefits. From (34) it is clear that this effect is given by $s / w$ for $j=w, u / w$ for $j=u$ and $n / w$ for $j=n$. The remaining terms in (37)

\footnotetext{
${ }^{14}$ This argument holds only locally, hence the qualification 'slightly'. A small change in $Q$ or $R$ has no direct effect on welfare, by the envelope theorem.
} 
capture the behavioral responses to benefit changes. It is assumed that the second-order conditions for an interior solution are satisfied.

\subsubsection{Is Benefit Differentiation Optimal?}

The question that we wish to shed light on is whether there is a case for benefit differentiation across the three states of non-work. There is a general presumption that such differentiation may be optimal since the behavioral responses to benefit changes differ across the states of interest. However, it is not clear whether something specific can be said about the optimal benefit structure without adding additional information on the key parameters.

We focus on two cases corresponding to different assumptions about the feasibility of monitoring job search. If monitoring is impossible, it is also impossible to differentiate benefits between workers who search and those who don't. The second case presupposes that monitoring is feasible so that benefit differentiation between unemployed job searchers and nonparticipants is possible.

Sickness Benefits versus Nonemployment Benefits. Let $\rho^{o}=\rho^{u}=\rho^{n}$ represent nonemployment benefits and $o \equiv u+n=1-e$ total nonemployment. The first-order conditions are then:

$$
\begin{aligned}
& \frac{d \Omega}{d \rho^{s}}=s-\frac{1}{1+t^{\prime}}\left[\frac{s}{w}+\rho^{s} \frac{d(s / w)}{d \rho^{s}}+\rho^{o} \frac{d(o / w)}{d \rho^{s}}\right]=0 \\
& \frac{d \Omega}{d \rho^{o}}=o-\frac{1}{1+t^{\prime}}\left[\frac{o}{w}+\rho^{s} \frac{d(s / w)}{d \rho^{o}}+\rho^{o} \frac{d(o / w)}{d \rho^{o}}\right]=0
\end{aligned}
$$

To determine whether benefit differentiation is optimal we assume that (39) holds and check whether (38) holds as an equality for $\rho^{s}=\rho^{o}$. Substitute out the tax factor and obtain following expression:

$$
\operatorname{sign}\left(\frac{d \Omega}{d \rho^{s}}\right)_{\rho^{s}=\rho^{o}}=\operatorname{sign}\left[\frac{s}{o}-\left(\frac{s-d \ln w / d \ln \rho^{s}}{o-d \ln w / d \ln \rho^{o}}\right)\right]
$$

A uniform benefit structure is not optimal if the derivative given by (40) is non-zero. If the derivative is positive, sickness benefits should be increased 
so as to achieve $\rho^{s}>\rho^{o}$; if it is negative, sickness benefits should be reduced to obtain $\rho^{s}<\rho^{o}$.

The first term in the brackets is the ratio between the marginal social utilities of increasing sickness and nonemployment benefits, respectively. The higher sickness is relative to nonemployment, the higher the value of raising sickness benefits relative to nonemployment benefits. The second term in the brackets is the ratio between the tax effects of higher sickness and nonemployment benefits, i.e.,

$$
\frac{d t^{\prime} / d \rho^{s}}{d t^{\prime} / d \rho^{o}}=\frac{s-d \ln w / d \ln \rho^{s}}{o-d \ln w / d \ln \rho^{o}}
$$

Absent moral hazard we have $d \ln w / d \ln \rho^{j}=0$ and it is straightforward to verify that the optimal policy involves uniform benefits and full insurance, i.e., $\rho^{s}=\rho^{o}=1$. The optimal policy with moral hazard takes the effects on the tax base into account. The larger the relative tax cost of higher sickness benefits, the more likely that expression (40) is negative and that sickness benefits should be set lower than nonemployment benefits. We assume that the problem is well-behaved so that the tax base is decreasing in $\rho^{s}$ as well as $\rho^{o} .^{15}$

After further simplifications we state the following proposition:

Proposition 3 Sickness benefits should be set higher than nonemployment benefits provided that the inequality

$$
o\left(\frac{d \ln w}{d \ln \rho^{s}}\right)-s\left(\frac{d \ln w}{d \ln \rho^{o}}\right)>0
$$

holds.

Proof Use (38) and (39) to derive (40) and simplify.

The case for benefit differentiation thus hinges on whether the groups of interest, sickness absentees and nonemployed, differ in size and/or whether the elasticities of the tax base differ between benefits types. Focusing on the case with $\phi^{w}=\phi^{s}$, we compute $d \ln w / d \ln \rho^{s}$ and $d \ln w / d \ln \rho^{o}$ and obtain

\footnotetext{
${ }^{15}$ Note however that the positive analysis could not unambiguosly determine the sign of $d \ln w / d \ln \rho^{s}$.
} 


$$
\operatorname{sign}\left(\frac{d \Omega}{d \rho^{s}}\right)_{\rho^{s}=\rho^{o}}=\operatorname{sign}\left\{\left(\alpha^{u}-\alpha^{n}\right)^{2}\left[F(Q)(1-F(Q))-F(R)^{2}\right]-\tilde{\alpha} \phi\right\}
$$

where it is assumed that $f(Q) \approx f(R)$. Although the sign is generally ambiguous, it is negative for realistic values for sickness absence rates. Note that $F(Q)(1-F(Q))-F(R)^{2}<0$ is a sufficient condition that should easily hold. ${ }^{16}$ In this case, therefore, sickness benefits should be lower than nonemployment benefits.

Unemployment Benefits versus Sickness Assistance. We proceed to examine whether there is a case for benefit differentiation between unemployed individuals and the nonparticipants. The first-order conditions for $\rho^{u}$ and $\rho^{n}$ are:

$$
\begin{aligned}
& \frac{d \Omega}{d \rho^{u}}=u-\frac{1}{1+t^{\prime}}\left[\frac{u}{w}+\rho^{s} \frac{d(s / w)}{d \rho^{u}}+\rho^{u} \frac{d(u / w)}{d \rho^{u}}+\rho^{n} \frac{d(n / w)}{d \rho^{u}}\right]=0 \\
& \frac{d \Omega}{d \rho^{n}}=n-\frac{1}{1+t^{\prime}}\left[\frac{n}{w}+\rho^{s} \frac{d(s / w)}{d \rho^{n}}+\rho^{u} \frac{d(u / w)}{d \rho^{n}}+\rho^{n} \frac{d(n / w)}{d \rho^{n}}\right]=0
\end{aligned}
$$

No assumption concerning $\rho^{s}$ is made; $\rho^{s}$ may or may not be optimally determined. Since active search boosts job finding, there is a presumption that unemployment benefits should be higher than sickness assistance. However, this outcome is not immediately obvious in the model; note, for example, that the optimal solution generally depends on $\rho^{s}$ as well as on how sickness absence among employees responds to nonemployment benefits.

To examine whether the presumption is valid we need to resort to a formal analysis. The following proposition can be established:

Proposition 4 The optimal benefit system involves $\rho^{u}>\rho^{n}$ provided that monitoring of job search is feasible.

\footnotetext{
${ }^{16}$ Observed sickness absence rates are lower than 0.10 so $F(Q)(1-F(Q))$ should be lower than $0.0 \dot{9}$. In this case the fraction of searchers among the nonemployed, i.e., $F(R)$, can be as low as 0.3 without violating the sufficient condition.
} 
Proof (Sketch; see Appendix C for details). Assume that (44) holds for $\rho^{u}=\rho^{n}$ and check whether (43) also holds as an equality for uniform benefits. After some calculations we obtain

$$
\operatorname{sign}\left(\frac{d \Omega}{d \rho^{u}}\right)_{\rho^{u}=\rho^{n}}=\operatorname{sign}\left(\frac{d R}{d \rho^{u}}-\frac{d R}{d \rho^{n}}\right)>0
$$

which is unambiguously positive since $d R / d \rho^{u}>0$ and $d R / d \rho^{n}<0$.

The simple intuition for this result is that the nonemployed individual ignores the fact that search is associated with a positive fiscal externality: additional search implies additional hirings and ultimately a rise in employment and the tax base. Unemployment benefits should be set higher than sickness assistance in order to correct for this externality. The problem is more involved than what the simple intuition conveys, however. It is noteworthy that conditions pertaining to employees, such as $\rho^{s}$ and the responsiveness of sickness absence to nonemployment benefits, $d(s / w) / d \rho^{u}$ and $d(s / w) / d \rho^{n}$, do not affect the qualitative outcome. It also turns out that the effects operating via $Q$ on $u / w$ and $n / w$ cancel exactly. See Appendix C for details.

\section{Concluding Remarks}

The paper has proposed a tractable framework for analyzing sickness absence and unemployment in a unified fashion and applied it to an analysis of social insurance policies. The analysis identifies channels whereby insurance benefits affect worker flows across labor force states and the implied steady-state allocation of workers across these states. A number of predictions emerge from the positive analysis, some less obvious than others. It is unsurprising that higher unemployment benefits will cause higher unemployment but less expected that higher sickness benefits for employees will have the same qualitative effect. The analysis also predicts that higher unemployment benefits will generally increase the sickness absence rate among employees. Moreover, it is noteworthy that higher unemployment benefits as well as higher sickness benefits will increase total employment when stringent employment 
protection legislation makes it impossible to punish absent workers by means of higher firing risks.

The most clear-cut result from the normative analysis is that unemployment benefits should be set higher than sickness assistance so as to foster active job search. This requires that monitoring of job search is feasible, of course. Existing unemployment insurance schemes involve some degree of monitoring, a fact that indicates that the optimal policy may be feasible to implement in practice. Real-world social insurance schemes often lack financial penalties associated with sick reporting among unemployed individuals, a feature at odds with our result.

The normative analysis is more ambiguous concerning the rationale for benefit differentiation between employed and nonemployed workers. Although real-world schemes often provide higher benefits to employed sick absentees than to nonemployed individuals reporting sick, there is nothing in our formal analysis suggesting that this should be optimal. This may perhaps reflect that the model ignores important elements of real-world sickness insurance schemes, such as monitoring of health by insurance providers and/or firms. ${ }^{17}$

The framework can be extended in various directions. It would, for example, be straightforward to introduce decision-making along the intensive margins. One might also consider an extension with endogenous wage determination and with an explicit role for firms in the decisions on hirings and firings. Finally, one would in a more complete normative analysis of sickness insurance allow for some degree of monitoring of health. Medical certification plays a role in real-world sickness insurance schemes although it does not eliminate all private information about health conditions.

\footnotetext{
${ }^{17}$ To exemplify, a Finnish or German employee must contact a medical doctor within the first three days of a sickness spell.
} 


\section{Appendix A: Flow Equilibrium}

The equations for the flow equilibrium are:

$$
\begin{aligned}
\phi^{w} w+\left(1-\phi^{w}\right)[1-F(Q)] w & =F(Q)\left(\alpha^{u} u+\alpha^{n} n+s-\phi^{s} s\right) \\
\phi^{s} s+\left(1-\phi^{s}\right) F(Q) s & =[1-F(Q)]\left(\alpha^{u} u+\alpha^{n} n+w-\phi^{w} w\right) \\
\alpha^{u} u+\left(1-\alpha^{u}\right)[1-F(R)] u & =F(R)\left(\phi^{w} w+\phi^{s} s+n-\alpha^{n} n\right) \\
w+u+s+n & =1
\end{aligned}
$$

The first equation equalizes outflows from and inflows to work $(w)$, the second correspond to sick absence $(s)$, the third to unemployment $(u)$ and the final expression determines nonparticipation $(n)$ residually from the population identity. The solution of this system is given in the text.

\section{Appendix B: Sickness Benefits and Sickness Absence}

Sickness benefits have ambiguous effects on the number of individuals at work. To examine this issue in more detail, decompose the elasticity $d \ln w / d b^{s}$ as follows:

$$
\frac{d \ln w}{d b^{s}}=\frac{d \ln F(Q)}{d b^{s}}+(1-e)\left(\frac{d \ln \tilde{\alpha}}{d b^{s}}-\frac{d \ln \tilde{\phi}}{d b^{s}}\right)
$$

where $d \ln F(Q) / d b^{s}=-f(Q) /(a-1) F(Q)<0$ and the second term captures the employment effect, i.e., $d \ln e / d b^{s}$. We have $d \ln \tilde{\phi} / d b^{s} \geq$ as $\phi^{s} \geq \phi^{w}$. Assume $\phi^{s}=\phi^{w}$ and compute the effect on the hiring rate:

$$
\frac{d \ln \tilde{\alpha}}{d b^{s}}=\frac{\left(\alpha^{u}-\alpha^{n}\right)^{2} f(R)[1-F(Q)]}{(a-1)(\tilde{\alpha}+\phi+r) \tilde{\alpha}}>0
$$

The sign-condition of interest is then as follows:

$$
\begin{aligned}
\operatorname{sign}\left(\frac{d \ln w}{d b^{s}}\right)= & \operatorname{sign}\left\{-\left(\alpha^{u}-\alpha^{n}\right) 2 F(R)-\alpha^{n}(\phi+r)\right. \\
& -\left(\alpha^{u}-\alpha^{n}\right)^{2} F(R)^{2} \\
& \left.+\left(\alpha^{u}-\alpha^{n}\right)^{2}(1-e)[1-F(Q)] F(Q) f(R) / f(Q)\right\}
\end{aligned}
$$


Consider two cases: (i) if $F(\theta)$ is uniform we have $f(R)=f(Q)$; (ii) if $F(\theta)$ is exponential it is true that $f(R) / f(Q)=[1-F(R)] /[1-F(Q)]$. In either case the expression can safely be taken as negative for realistic values of employment and sickness absence rates. ${ }^{18}$ The sign-prediction would be further corroborated if firing risks were absence-dependent, i.e., $\phi^{s}>\phi^{w}$.

\section{Appendix C: Differentiated Nonemployment Benefits}

We are interested in whether the objective function is increasing in $\rho^{u}$ when evaluated at $\rho^{u}=\rho^{n}$. By using eqs. (43) and (44) we can write the expression of interest as

$$
\operatorname{sign}\left(\frac{d \Omega}{d \rho^{u}}\right)_{\rho^{u}=\rho^{n}}=\operatorname{sign}\left[\frac{u}{n}-\frac{\frac{u}{w}+\rho^{s} \frac{d(s / w)}{d \rho^{u}}+\rho^{u} \frac{d(u / w)}{d \rho^{u}}+\rho^{n} \frac{d(n / w)}{d \rho^{u}}}{\frac{n}{w}+\rho^{s} \frac{d(s / w)}{d \rho^{n}}+\rho^{u} \frac{d(u / w)}{d \rho^{n}}+\rho^{n} \frac{d(n / w)}{d \rho^{n}}}\right]
$$

which also can be written as

$\operatorname{sign}\left(\frac{d \Omega}{d \rho^{u}}\right)_{\rho^{u}=\rho^{n}}=\operatorname{sign}\left[\rho^{s}\left(\frac{u}{n} \frac{d(s / w)}{d \rho^{n}}-\frac{d(s / w)}{d \rho^{u}}\right)+\rho^{o}\left(\frac{u}{n} \frac{d(o / w)}{d \rho^{n}}-\frac{d(o / w)}{d \rho^{u}}\right)\right]$

The first term in the squared brackets captures how changes in $\rho^{n}$ and $\rho^{u}$ affect sickness absence among employees. It turns out that the two terms cancel exactly since

$$
\frac{d(s / w) d \rho^{u}}{d(s / w) d \rho^{n}}=\frac{d Q / d \rho^{u}}{d Q / d \rho^{n}}=\frac{F(R)}{1-F(R)}=\frac{u}{n}
$$

The sign is thus determined by the second term in the brackets. This can be written as

$$
\operatorname{sign}\left(\frac{d \Omega}{d \rho^{u}}\right)_{\rho^{u}=\rho^{n}}=\operatorname{sign}\left(\rho^{o} \frac{d(o / w)}{d \rho^{n}}\right)\left[\frac{u}{n}-\frac{d(o / w) / d \rho^{u}}{d(o / w) / d \rho^{n}}\right]
$$

and by making use of the derivative expressions for $d(o / w) / d \rho^{u}$ and $d(o / w) / d \rho^{n}$ we obtain the condition stated in proposition 4 (note that $d(o / w) / d \rho^{n}>0$ ).

\footnotetext{
${ }^{18}$ Note that $\left[F(R)^{2}-(1-e)(1-F(Q)) F(Q)\right]>0$ is a sufficient condition for a negative sign in the first case whereas $\left[F(R)^{2}-(1-e)(1-F(R)) F(Q)\right]>0$ is sufficient in the second case.
} 


\section{References}

Allen, S. (1981), An Empirical Model of Work Attendance, Review of Economics and Statistics 63, 77-87.

Arai, M. and Skogman Thoursie, P. (2001), Incentive or Selection in Cyclical Absenteeism, Working Paper 167, Trade Union Institute for Economic Research. Forthcoming in Labour Economics.

Askildsen J., Bratberg E. and Nilsen Ø. A. (2002), Unemployment, Labour Force Composition and Sickness Absence: A Panel Data Study, IZA Discussion Papers, No. 466.

Barmby, T., Orme, C. and Treble, J. (1991), Worker Absenteeism: a Study Using Microdata, Economic Journal 101, 214-229.

Barmby, T., Sessions, J. and Treble J. (1994), Absenteeism, Efficiency Wages and Shirking, Scandinavian Journal of Economics 96, 561-566.

Boone, J., Fredriksson, P., Holmlund, B. and van Ours, J. (2002), Optimal Unemployment Insurance with Monitoring and Sanctions, Working Paper, Institute for Labour Market Policy Evaluation (IFAU).

Broström, G., Johansson, P. and Palme, M. (2004), Economic Incentives and Gender Differences in Work Absence Behaviour, Swedish Economic Policy Review 11, 33-63.

Brown, S. and Sessions, J. (1996), The Economics of Absence: Theory and Evidence, Journal of Economic Surveys 10, 23-53.

Burdett, K., Kiefer, N., Mortensen, D. and Neumann G. (1984), Earnings, Unemployment, and the Allocation of Time Over Time, Review of Economic Studies 51, 559-578.

Ehrenberg, R. (1970), Absenteeism and the Overtime Decision, American Economic Review 60, 352-357. 
Flinn, C. and Heckman, J. (1982), New Methods for Analyzing Structural Models of Labor Force Dynamics, Journal of Econometrics 18, 115-168.

Flinn, C. and Heckman, J. (1983), Are Unemployment and Out of the Labor Force Behaviorally Distinct Labor Force States? Journal of Labor Economics 1, 28-42.

Garibaldi, P. and Wasmer, E. (2001), Labor Market Flows and Equlibrium Search Unemployment, IZA Discussion Paper no 406.

Henreksson, M. and Persson, M. (2004), The Effects of Sick Leave of Changes in the Sickness Insurance System, Journal of Labor Economics 22, 87113.

Hesselius P. (2003), Does Sick Absence Increase the Risk of Unemployment?, Working Paper 2003:15, Department of Economics, Uppsala University.

Ichino, A. and Riphahn, R. (2003), The Effect of Employment Protection on Worker Effort. A Comparison of Absenteeism During and After Probation, CEPR Discussion Paper 3847. Forthcoming in Journal of the European Economic Association.

Ichino, A. and Riphahn, R. (2004), Absenteeism and Employment Protection: Three Case Studies, Swedish Economic Policy Review 11, 95-114.

Johansson, P. and Palme, M. (1996), Do Economic Incentives Affect Worker Absence? Empirical Evidence Using Swedish Data, Journal of Public Economics 59, 195-218.

Johansson, P. and Palme, M. (2002), Assessing the Effect of Public Policy on Worker Absenteeism, Journal of Human Resources, 37, 381-409.

Kangas, O. (1991), The Politics of Social Rights. Studies in the Dimensions of Sickness Insurance in the OECD Countries, Ph.D. Thesis, Swedish Institute for Social Research, Stockholm. 
Larsson, L. (2002), Sick of Being Unemployed? Interactions Between Unemployment and Sickness Insurance in Sweden, Working Paper 2002:6, Institute for Labour Market Policy Evaluation (IFAU).

Larsson, L (2004), Harmonizing Sickness and Unemployment Insurance: Why (Not)? Swedish Economic Policy Review 11, 151-188.

Lindbeck, A., Molander, P., Persson, T., Petersson, O., Sandmo, A., Swedenborg, B. and Thygesen, N. (1994), Turning Sweden Around, MIT Press.

Mortensen, D. (1977), Unemployment Insurance and Job Search Decisions, Industrial and Labor Relations Review, 30, 505-517.

Nyman, K., Bergendorff, S. and Palmer, E. (2002), Den svenska sjukan sjukfrånvaron i åtta länder (Sickness in Sweden - sickness absence in eight countries), ESO Report Ds 2002:49, Ministry of Finance, Stockholm.

Riksförsäkringsverket (2003), Regionala skillnader i sjukskrivning - hur ser de ut och vad beror de på? (Regional differences in sickness reporting - patterns and causes), RFV ANALYSERAR 2003:12, The National Social Insurance Board, Stockholm.

Toikka, R. (1976), A Markovian Model of Labor Market Decisions by Workers, American Economic Review 66, 821-834. 


\section{CESifo Working Paper Series}

(for full list see www.cesifo.de)

1160 Romain Ranciere, Aaron Tornell, and Frank Westermann, Crises and Growth: A ReEvaluation, March 2004

1161 Assaf Razin and Efraim Sadka, Transparency, Specialization and FDI, March 2004

1162 Ludger Woessmann, How Equal Are Educational Opportunities? Family Background and Student Achievement in Europe and the United States, March 2004

1163 B.M.S. van Praag and Barbara E. Baarsma, Using Happiness Surveys to Value Intangibles: The Case of Airport Noise, March 2004

1164 Aaron Tornell, Frank Westermann, and Lorenza Martínez, The Positive Link Between Financial Liberalization, Growth, and Crises, March 2004

1165 Helge Berger and Carsten Hefeker, One Country, One Vote? Labor Market Structure and Voting Rights in the ECB, March 2004

1166 Clemens Fuest and Martin Kolmar, A Theory of User-Fee Competition, March 2004

1167 Friedrich Schneider and Robert Klinglmair, Shadow Economies around the World: What Do We Know?, April 2004

1168 Horst Raff and Nicolas Schmitt, Exclusive Dealing and Common Agency in International Markets, April 2004

1169 M. Hashem Pesaran and Allan Timmermann, Real Time Econometrics, April 2004

1170 Sean D. Barrett, Privatisation in Ireland, April 2004

1171 V. Anton Muscatelli, Patrizio Tirelli and Carmine Trecroci, Can Fiscal Policy Help Macroeconomic Stabilisation? Evidence from a New Keynesian Model with Liquidity Constraints, April 2004

1172 Bernd Huber and Marco Runkel, Tax Competition, Excludable Public Goods and User Charges, April 2004

1173 John McMillan and Pablo Zoido, How to Subvert Democracy: Montesinos in Peru, April 2004

1174 Theo Eicher and Jong Woo Kang, Trade, Foreign Direct Investment or Acquisition: Optimal Entry Modes for Multinationals, April 2004

1175 Chang Woon Nam and Doina Maria Radulescu, Types of Tax Concessions for Attracting Foreign Direct Investment in Free Economic Zones, April 2004 
1176 M. Hashem Pesaran and Andreas Pick, Econometric Issues in the Analysis of Contagion, April 2004

1177 Steinar Holden and Fredrik Wulfsberg, Downward Nominal Wage Rigidity in Europe, April 2004

1178 Stefan Lachenmaier and Ludger Woessmann, Does Innovation Cause Exports? Evidence from Exogenous Innovation Impulses and Obstacles, April 2004

1179 Thiess Buettner and Johannes Rincke, Labor Market Effects of Economic Integration The Impact of Re-Unification in German Border Regions, April 2004

1180 Marko Koethenbuerger, Leviathans, Federal Transfers, and the Cartelization Hypothesis, April 2004

1181 Michael Hoel, Tor Iversen, Tore Nilssen, and Jon Vislie, Genetic Testing and Repulsion from Chance, April 2004

1182 Paul De Grauwe and Gunther Schnabl, Exchange Rate Regimes and Macroeconomic Stability in Central and Eastern Europe, April 2004

1183 Arjan M. Lejour and Ruud A. de Mooij, Turkish Delight - Does Turkey's accession to the EU bring economic benefits?, May 2004

1184 Anzelika Zaiceva, Implications of EU Accession for International Migration: An Assessment of Potential Migration Pressure, May 2004

1185 Udo Kreickemeier, Fair Wages and Human Capital Accumulation in a Global Economy, May 2004

1186 Jean-Pierre Ponssard, Rent Dissipation in Repeated Entry Games: Some New Results, May 2004

1187 Pablo Arocena, Privatisation Policy in Spain: Stuck Between Liberalisation and the Protection of Nationals' Interests, May 2004

1188 Günter Knieps, Privatisation of Network Industries in Germany: A Disaggregated Approach, May 2004

1189 Robert J. Gary-Bobo and Alain Trannoy, Efficient Tuition Fees, Examinations, and Subsidies, May 2004

1190 Saku Aura and Gregory D. Hess, What's in a Name?, May 2004

1191 Sjur Didrik Flåm and Yuri Ermoliev, Investment Uncertainty, and Production Games, May 2004

1192 Yin-Wong Cheung and Jude Yuen, The Suitability of a Greater China Currency Union, May 2004 
1193 Inés Macho-Stadler and David Pérez-Castrillo, Optimal Enforcement Policy and Firms' Emissions and Compliance with Environmental Taxes, May 2004

1194 Paul De Grauwe and Marianna Grimaldi, Bubbles and Crashes in a Behavioural Finance Model, May 2004

1195 Michel Berne and Gérard Pogorel, Privatization Experiences in France, May 2004

1196 Andrea Galeotti and José Luis Moraga-González, A Model of Strategic Targeted Advertising, May 2004

1197 Hans Gersbach and Hans Haller, When Inefficiency Begets Efficiency, May 2004

1198 Saku Aura, Estate and Capital Gains Taxation: Efficiency and Political Economy Consideration, May 2004

1199 Sandra Waller and Jakob de Haan, Credibility and Transparency of Central Banks: New Results Based on Ifo's World Economicy Survey, May 2004

1200 Henk C. Kranendonk, Jan Bonenkamp, and Johan P. Verbruggen, A Leading Indicator for the Dutch Economy - Methodological and Empirical Revision of the CPB System, May 2004

1201 Michael Ehrmann, Firm Size and Monetary Policy Transmission - Evidence from German Business Survey Data, May 2004

1202 Thomas A. Knetsch, Evaluating the German Inventory Cycle - Using Data from the Ifo Business Survey, May 2004

1203 Stefan Mittnik and Peter Zadrozny, Forecasting Quarterly German GDP at Monthly Intervals Using Monthly IFO Business Conditions Data, May 2004

1204 Elmer Sterken, The Role of the IFO Business Climate Indicator and Asset Prices in German Monetary Policy, May 2004

1205 Jan Jacobs and Jan-Egbert Sturm, Do Ifo Indicators Help Explain Revisions in German Industrial Production?, May 2004

1206 Ulrich Woitek, Real Wages and Business Cycle Asymmetries, May 2004

1207 Burkhard Heer and Alfred Maußner, Computation of Business Cycle Models: A Comparison of Numerical Methods, June 2004

1208 Costas Hadjiyiannis, Panos Hatzipanayotou, and Michael S. Michael, Pollution and Capital Tax Competition within a Regional Block, June 2004

1209 Stephan Klasen and Thorsten Nestmann, Population, Population Density, and Technological Change, June 2004

1210 Wolfgang Ochel, Welfare Time Limits in the United States - Experiences with a New Welfare-to-Work Approach, June 2004 
1211 Luis H. R. Alvarez and Erkki Koskela, Taxation and Rotation Age under Stochastic Forest Stand Value, June 2004

1212 Bernard M. S. van Praag, The Connexion Between Old and New Approaches to Financial Satisfaction, June 2004

1213 Hendrik Hakenes and Martin Peitz, Selling Reputation When Going out of Business, June 2004

1214 Heikki Oksanen, Public Pensions in the National Accounts and Public Finance Targets, June 2004

1215 Ernst Fehr, Alexander Klein, and Klaus M. Schmidt, Contracts, Fairness, and Incentives, June 2004

1216 Amihai Glazer, Vesa Kanniainen, and Panu Poutvaara, Initial Luck, Status-Seeking and Snowballs Lead to Corporate Success and Failure, June 2004

1217 Bum J. Kim and Harris Schlesinger, Adverse Selection in an Insurance Market with Government-Guaranteed Subsistence Levels, June 2004

1218 Armin Falk, Charitable Giving as a Gift Exchange - Evidence from a Field Experiment, June 2004

1219 Rainer Niemann, Asymmetric Taxation and Cross-Border Investment Decisions, June 2004

1220 Christian Holzner, Volker Meier, and Martin Werding, Time Limits on Welfare Use under Involuntary Unemployment, June 2004

1221 Michiel Evers, Ruud A. de Mooij, and Herman R. J. Vollebergh, Tax Competition under Minimum Rates: The Case of European Diesel Excises, June 2004

1222 S. Brock Blomberg and Gregory D. Hess, How Much Does Violence Tax Trade?, June 2004

1223 Josse Delfgaauw and Robert Dur, Incentives and Workers' Motivation in the Public Sector, June 2004

1224 Paul De Grauwe and Cláudia Costa Storti, The Effects of Monetary Policy: A MetaAnalysis, June 2004

1225 Volker Grossmann, How to Promote R\&D-based Growth? Public Education Expenditure on Scientists and Engineers versus R\&D Subsidies, June 2004

1226 Bart Cockx and Jean Ries, The Exhaustion of Unemployment Benefits in Belgium. Does it Enhance the Probability of Employment?, June 2004

1227 Bertil Holmlund, Sickness Absence and Search Unemployment, June 2004 